\title{
Comparative Phenotypic and
} Genotypic Analysis of Swiss and Finnish Listeria monocytogenes Isolates with Respect to Benzalkonium Chloride Resistance

\author{
Anja B. Meier ${ }^{1}$, Claudia Guldimann ${ }^{1}$, Annukka Markkula ${ }^{2}$, Anna Pöntinen ${ }^{2}$, \\ Hannu Korkeala ${ }^{2}$ and Taurai Tasara ${ }^{1 *}$ \\ ${ }^{1}$ Institute for Food Safety and Hygiene, Vetsuisse Faculty University of Zurich, Zurich, Switzerland, ${ }^{2}$ Department of Food \\ Hygiene and Environmental Health, Faculty of Veterinary Medicine, University of Helsinki, Helsinki, Finland
}

OPEN ACCESS

Edited by:

Juan Aguirre,

Universidad de Chile, Chile

Reviewed by:

Laurent Guillier,

French Agency for Food,

Environmental and Occupational

Health \& Safety (ANSES), France

Julio Parra-Flores,

University of the Bio Bío, Chile

Catherine Maeve Burgess,

Teagasc - The Irish Agriculture and

Food Development Authority, Ireland

*Correspondence:

Taurai Tasara

tasarat@fsafety.uzh.ch

Specialty section: This article was submitted to

Food Microbiology,

a section of the journal

Frontiers in Microbiology

Received: 21 October 2016

Accepted: 27 February 2017

Published: 23 March 2017

Citation:

Meier AB, Guldimann C, Markkula A, Pöntinen A, Korkeala $H$ and Tasara $T$

(2017) Comparative Phenotypic and

Genotypic Analysis of Swiss and

Finnish Listeria monocytogenes

Isolates with Respect to Benzalkonium

Chloride Resistance.

Front. Microbiol. 8:397.

doi: 10.3389/fmicb.2017.00397
Reduced susceptibility of Listeria monocytogenes to benzalkonium chloride (BC), a quaternary ammonium compound widely used in food processing and hospital environments, is a growing public health and food safety concern. The minimal inhibitory concentration of BC on 392 L. monocytogenes strains from Switzerland $(\mathrm{CH})$ and Finland (FIN) was determined. Within this strain collection, benzalkonium chloride resistance was observed in 12.3\% (24/195) of Swiss and 10.6\% (21/197) of Finnish strains. In both countries, the highest prevalence of BC-resistant strains ( $\mathrm{CH}: 29.4 \%$; FIN: 38.9\%) was detected among serotype 1/2c strains. Based on PCR analysis, genes coding for the qacH efflux pump system were detected for most of the BC-resistant strains $(\mathrm{CH}$ : 62.5\%; FIN: 52.4\%). Some Swiss BC-resistant strains harbored genes coding for the bcrABC (16.7\%) efflux pump system, while one Finnish BC-resistant strain harbored the emrE gene previously only described among BC-resistant $L$. monocytogenes strains from Canada. Interestingly, a subset of BC-resistant strains $(\mathrm{CH}: 5 / 24,20.8 \%$; FIN: 9/21, 42.8\%) lacked genes for efflux pumps currently known to confer BC resistance in $L$. monocytogenes. BC resistance analysis in presence of reserpine showed that the resistance was completely or partially efflux pump dependent in 10 out of the 14 strains lacking the known BC resistance genes. Sequence types 155 and ST403 were over-representated among these strains suggesting that these strains might share similar but yet unknown mechanisms of $\mathrm{BC}$ resistance.

Keywords: Listeria monocytogenes, benzalkonium chloride, bcrABC, qacH, emrE, MLST

\section{INTRODUCTION}

Listeria monocytogenes, the causative agent of listeriosis in humans and animals, represents a major foodborne pathogen with serious impacts on public health and the food industry (de Valk et al., 2005; Popovic et al., 2014; Crim et al., 2015). Listeriosis mainly, but not exclusively affects neonates, elderly people, pregnant women, and immunosuppressed individuals and may cause gastroenteritis, sepsis, central nervous system infections, and abortion in pregnant women 
(Maertens de et al., 2014). Listeriosis, even though relatively rare, occurs worldwide (Maertens de et al., 2014) and is of major public health concern due to the high case-fatality rate in human clinical cases (15-30 deaths/100 cases; Crim et al., 2015; de Valk et al., 2005; Popovic et al., 2014). The ubiquitous nature of L. monocytogenes and its ability to grow at refrigeration temperatures (Walker et al., 1990) and to tolerate very low $\mathrm{pH}$ (reviewed in Smith et al., 2013) and high salt concentrations (Bergholz et al., 2010), increases the risk of foodborne outbreaks from strains that achieve high concentrations on products with a long shelf life and subsequently cause human infections upon consumption. Strains of L. monocytogenes can persist in niches within food processing facilities for years, representing a serious food safety issue (reviewed in Ferreira et al., 2014). As a preventive measure, quaternary ammonium compounds (QACs) such as benzalkonium chloride (BC), are widely used for cleaning and disinfection of food processing environments (McDonnell and Russell, 1999; Mereghetti et al., 2000). Quaternary ammonium compounds function by disrupting cell membranes of bacteria, subsequently leading to leakage of the cytosol, and degradation of proteins as well as nucleic acids (McDonnell and Russell, 1999). L. monocytogenes strains with low susceptibility to BC have been regularly isolated from foods and food processing environments. (Mereghetti et al., 2000; Romanova et al., 2002; Mullapudi et al., 2008; Fox et al., 2011)., Benzalkonium chloride resistant $\left(\mathrm{BC}^{\mathrm{r}}\right)$ strains have been isolated from human listeriosis infections (Elhanafi et al., 2010), and there is evidence of cross-protection against other antimicrobials including gentamicin and ciprofloxacin (Rakic-Martinez et al., 2011). In light of this, the presence of $\mathrm{BC}^{\mathrm{r}}$ strains in food and food processing environments is concerning.

The known molecular mechanisms of BC resistance are due to the activity of efflux pump systems encoded through the brcABC (Elhanafi et al., 2010), qacH on the Tn6188 transposon (Müller et al., 2013), and emrE (Gilmoure et al., 2010; Kovacevic et al., 2015) genes that can be acquired by horizontal gene transfer leading to $\mathrm{BC}$ resistance in L. monocytogenes. There is limited knowledge of the prevalence of $\mathrm{BC}$ resistance among Swiss L. monocytogenes strains; a recent study found a prevalence of $18 \%$ among 142 Swiss strains isolated from food and the food processing environment (Ebner et al., 2015). Virtually no information is available on the QAC resistance profiles in strains from Finland. The aim of this study was to analyze and compare a large collection consisting of $L$. monocytogenes strains from Switzerland and Finland for BC susceptibility and the presence of known genes that convey resistance to QAC. The strain collection included isolates originating from samples taken along the whole length of the food production chain, ranging from the farm environment (silage, feces of farm animals, birds, and veterinary clinical cases) to food production facilities and various foods to human clinical cases.

\section{MATERIALS AND METHODS}

\section{Bacterial Strains}

The 392 L. monocytogenes strains used in this study were collected between 1999 and 2013 in Switzerland and Finland
(Supplementary Table 1). The Swiss strains $(n=195)$ were collected at the Swiss National Reference Centre for Enteropathogenic Bacteria and Listeria (NENT). This strain collection differed from that recently described in the study by Ebner et al. (2015). Finnish strains $(n=197)$ were collected through the Department of Food Hygiene and Environmental Health of the Faculty of Veterinary Medicine at the University of Helsinki. Unlike the Swiss strain collection, the Finnish strain collection lacked human clinical isolates. The origin of the strains was summarized as: dairy (strains isolated from dairy products), meat (strains isolated from carcasses and raw meat products), fish (strains isolated from raw fish), ready to eat (RTE) food (strains isolated from RTE seafood, salad, sausage, ham, maize products), vegetables (strains isolated from raw vegetables), food animals (strains isolated from cows, goats, pigs, and sheep), birds (strains isolated from the feces of wild birds), food production environments (FPE; strains isolated from meat, RTE and dairy production environments), human (strains isolated from human listeriosis cases), others (strains isolated from quorn, rice, silage). Bacteria were stored at $-80^{\circ} \mathrm{C}$ in brain heart infusion (BHI; Oxoid, Pratteln, Switzerland) broth plus 20\% glycerol (SigmaAldrich, Buchs, Switzerland).

\section{Strain Serotyping and BC Susceptibility Testing}

Strain serotypes were assigned by the slide agglutination test using the commercial set of Listeria $\mathrm{O}$-factor and $\mathrm{H}$-factor antisera from Denka Seiken (Pharma Consulting, Burgdorf, Switzerland) according to the manufacturer's instructions. Susceptibility to BC was tested using the previously described agar dilution method (Elhanafi et al., 2010). Strains were plated on blood agar plates (Difco, Columbia blood agar base, 5\% sheep blood, Oxoid) and incubated for $18 \mathrm{~h}$ at $37^{\circ} \mathrm{C}$. Single colonies were picked from each plate on the next day and suspended in $100 \mu \mathrm{l}$ of Mueller Hinton broth (MHB; Oxoid, Pratteln, Switzerland). Five microliters of the suspensions were spotted in technical duplicates on Mueller Hinton Agar (MHA; Oxoid) plates supplemented with $2 \%$ defibrinated sheep blood (Oxoid) and various BC concentrations $(0,2.5,5,7.5,10$, $15,20,25$, and $30 \mu \mathrm{g} \mathrm{ml}^{-1}$; Sigma-Aldrich). Benzalkonium chloride minimal inhibitory concentrations (MICs) were read after incubating the plates at $37^{\circ} \mathrm{C}$ for $48 \mathrm{~h}$. Spots could exhibit either no growth, growth of individual colonies, or confluent growth over the full area of the spot. Strains were considered resistant to a given concentration of $\mathrm{BC}$ if the spots showed confluent growth, and the MIC was defined as the lowest $\mathrm{BC}$ concentration preventing confluent growth of the spotted bacteria. Strains were considered $\mathrm{BC}^{\mathrm{r}}$ if they exhibited confluent growth at or above $20 \mu \mathrm{g} \mathrm{ml}^{-1}$. This cutoff was defined after the following considerations: we first determined the lowest BC concentration that killed $>50 \%$ of all strains $\left(10 \mu \mathrm{g} \mathrm{ml}^{-1}\right)$. Based on (Langsrud et al. (2003); Xu et al. (2014), we then defined resistance at a MIC that was double this concentration $\left(20 \mu \mathrm{g} \mathrm{ml}^{-1}\right)$. Minimal inhibitory concentrations are indicated as $>30 \mu \mathrm{g} \mathrm{ml}^{-1}$ for strains that exhibited confluent growth at 25 and $30 \mu \mathrm{g} \mathrm{ml}^{-1} \mathrm{BC}$. 


\section{Impact of Efflux Pump Inhibition with Reserpine On BC Susceptibility}

To assess the contribution of efflux pump activity in $\mathrm{BC}^{\mathrm{r}}$ strains, the BC MICs of such strains were also determined on MHB agar plates containing various $\mathrm{BC}$ concentrations $(0,2.5,5,7.5,10$, $15,20,25$, and $30 \mu \mathrm{g} \mathrm{ml}^{-1}$; Sigma-Aldrich) and supplemented with the efflux pump inhibitor reserpine $\left(20 \mu \mathrm{g} \mathrm{ml}^{-1}\right.$; SigmaAldrich; Romanova et al., 2006). The BC resistance of the L. monocytogenes strains was classified as not efflux dependent (no effect of reserpine on the BC MIC), partially efflux pump dependent (addition of reserpine resulted in a decrease of the BC MIC of $<10 \mu \mathrm{g} \mathrm{ml}^{-1}$ ), or fully efflux pump dependent (addition of reserpine resulted in a decrease of the BC MIC of $\geq 10 \mu \mathrm{g} \mathrm{ml}^{-1}$ ).

\section{Genetic Analysis of All BCr Strains}

The DNA templates were extracted from L. monocytogenes strains that were grown overnight in $\mathrm{BHI}$ broth $\left(37^{\circ} \mathrm{C}\right.$ and $\left.125 \mathrm{rpm}\right)$, using the DNeasy blood and tissue kit (Qiagen). Genotyping by multilocus sequence typing (MLST) was performed as previously described (Ragon et al., 2008). Polymerase chain reactions (PCRs) to amplify seven housekeeping genes were performed using the HotStartTaq Master Mix (Qiagen) and $50 \mathrm{ng}$ of genomic DNA template from each analyzed strain. The PCR products were sequenced at Microsynth (Balgach). The MLST types and genetic lineages were assigned using the L. monocytogenes MLST database website (http://bigsdb. web.pasteur.fr). The PCR analysis for the presence of $b c r A B C$, Tn6188, and emrE genes was performed as previously described using primers shown in Table 1. The emrE primers were designed based on L. monocytogenes strain sequence 05-5578 described by Gilmoure et al. (2010). The R56 and R159 L. monocytogenes strains (Ebner et al., 2015) were used as $b c r A B C$ and Tn6188 positive controls, respectively whereas the LR391 strain (Kovacevic et al., 2012) was used as a positive control for emrE.

\section{Statistical Analysis}

Statistical analysis was performed using the JMP program (Version 11.0.0, SAS Institute Inc., NC, USA). Fisher's exact test was used in a series of individual pairwise comparisons using $2 \times 2$ tables to compare proportions of $\mathrm{BC}^{\mathrm{r}}$ and $\mathrm{BC}^{\mathrm{s}}$ within the

TABLE 1 | Primers used in this study.

\begin{tabular}{lll}
\hline Primer & $\begin{array}{l}\text { Genetic Sequence }\left(5^{\prime}-3^{\prime}\right) \\
\text { target }\end{array}$ & References \\
\hline
\end{tabular}

\begin{tabular}{llll}
\hline p1 & bcrABC & CAT TAG AAG CAG TCG CAA AGC A & $\begin{array}{l}\text { Elhanafi et al., } \\
2010\end{array}$ \\
p2 & & GTT TTC GTG TCA GCA GAT CTT TGA & \\
radC fwd & Tn6188 & CTा GCC AAT GAT AAT ATC ATC & Müller et al.,
\end{tabular}

radC rev GTG GTC TGA ATG CTC CAT CG

EmrE fw emrE GAC CAA CAC CAC CTA AGT This study

EmrE $r \quad$ GTC TGA TGG ACT TAC AAA GCT serotypes and the sources per country. $P<0.05$ were considered to be statistically significant.

\section{RESULTS}

\section{Serotypes and Origins of Swiss and Finnish L. monocytogenes Strains}

A panel of 195 Swiss (CH) and 197 Finnish (FIN) L. monocytogenes strains that were isolated from diverse sources including foods, food production environments, food animals, wild birds, and human listeriosis cases was serotyped. Table 2 presents an overview of the distribution of these strains based on serotypes and isolation sources. Strains examined from these two countries belonged to serotypes 1/2a (CH: 105/195, 53.8\%, and FIN: 134/197, 68.0\%), 4b (CH: 47/195, 24.1\%; FIN: 23/197, 11.7\%), 1/2b (CH: 26/195, 13.3\%; FIN: 18/197, 9.1\%),

TABLE 2 | Distribution of the Swiss (CH) and Finnish (FIN)

L. monocytogenes strains based on serotypes and sources.

\begin{tabular}{|c|c|c|c|c|c|c|}
\hline \multirow[t]{2}{*}{ Source } & \multicolumn{6}{|c|}{ Number of $L$. monocytogenes strains within each serotype } \\
\hline & $1 / 2 a$ & $1 / 2 b$ & $1 / 2 c$ & $3 \mathbf{a}$ & $4 b$ & Total \\
\hline \multicolumn{7}{|c|}{ FOOD-ASSOCIATED ENVIRONMENT } \\
\hline $\mathrm{CH}$ & 9 & 1 & 1 & 0 & 4 & 15 \\
\hline FIN & 14 & 8 & 7 & 0 & 2 & 31 \\
\hline \multicolumn{7}{|c|}{ DAIRY PRODUCTS } \\
\hline $\mathrm{CH}$ & 10 & 3 & 0 & 0 & 3 & 16 \\
\hline FIN & 7 & 0 & 0 & 1 & 0 & 8 \\
\hline \multicolumn{7}{|c|}{ RAW VEGETABLES } \\
\hline $\mathrm{CH}$ & 1 & 0 & 0 & 0 & 0 & 1 \\
\hline FIN & 4 & 5 & 0 & 1 & 1 & 11 \\
\hline \multicolumn{7}{|c|}{ RTE FOODS } \\
\hline $\mathrm{CH}$ & 11 & 4 & 0 & 0 & 2 & 17 \\
\hline FIN & 2 & 0 & 1 & 0 & 0 & 3 \\
\hline \multicolumn{7}{|l|}{ MEAT } \\
\hline $\mathrm{CH}$ & 29 & 6 & 10 & 0 & 14 & 59 \\
\hline FIN & 54 & 3 & 9 & 0 & 3 & 69 \\
\hline \multicolumn{7}{|l|}{ FISH } \\
\hline $\mathrm{CH}$ & 1 & 1 & 0 & 0 & 0 & 2 \\
\hline FIN & 23 & 0 & 0 & 2 & 2 & 27 \\
\hline \multicolumn{7}{|c|}{ FOOD ANIMALS } \\
\hline $\mathrm{CH}$ & 1 & 0 & 0 & 0 & 0 & 1 \\
\hline FIN & 14 & 1 & 0 & 0 & 4 & 19 \\
\hline \multicolumn{7}{|l|}{ BIRDS } \\
\hline $\mathrm{CH}$ & 0 & 0 & 0 & 0 & 0 & 0 \\
\hline FIN & 13 & 1 & 1 & 0 & 10 & 25 \\
\hline \multicolumn{7}{|c|}{ HUMAN LISTERIOSIS } \\
\hline $\mathrm{CH}$ & 41 & 11 & 4 & 0 & 24 & 80 \\
\hline FIN & 0 & 0 & 0 & 0 & 0 & 0 \\
\hline \multicolumn{7}{|c|}{ OTHERS } \\
\hline $\mathrm{CH}$ & 2 & 0 & 1 & 1 & 0 & 4 \\
\hline FIN & 3 & 0 & 0 & 0 & 1 & 4 \\
\hline
\end{tabular}

Total (\%) 239 (61\%) 44 (11.2\%) 34 (8.7\%) 5 (1.3\%) 70 (17.9\%) 392 (100\%) 
1/2c (CH: 17/195, 8.7\%; FIN: 18/197, 9.1\%), and 3a (CH: 1/195, $0.5 \%$; FIN: $4 / 197,2.0 \%)$. In terms of isolation sources, the Swiss strains came from human listeriosis (80/195, 41.0\%), meat (59/195, 30.3\%), RTE food (17/195; 8.7\%), dairy (14/195, 7.2\%), FPE (17/195, 8.7\%), fish $(2 / 195,1.0 \%)$, food animals $(1 / 195$, $0.5 \%)$, vegetables $(1 / 195,0.5 \%)$, and other sources $(4 / 195,2.1 \%)$. Finnish strains originated from meat $(69 / 197,35 \%)$, FPE (31/197, $15.7 \%)$, fish $(27 / 197,13.7 \%)$, birds $(25 / 197,12.7 \%)$, food animals (19/197, 9.6\%), raw vegetables $(11 / 197,5.6 \%)$, dairy $(8 / 197$, $4.0 \%)$, RTE food (3/197, 1.5\%), and other sources (4/197, $2.0 \%)$.

\section{BC Susceptibility of the Swiss and Finnish L. monocytogenes Strains}

The BC susceptibility profiles of the Swiss and Finnish L. monocytogenes strains were assessed. Benzalkonium chloride MICs ranging from 7.5 to $>30 \mu \mathrm{g} \mathrm{ml}^{-1}$ were found (Figure 1; Table 2). Strains with BC MICs $\geq 20 \mu \mathrm{g} \mathrm{ml}^{-1}$ were classified as $\mathrm{BC}^{\mathrm{r}}$; strains with $\mathrm{BC} \mathrm{MICs}<20 \mu \mathrm{g} \mathrm{ml}^{-1}$ were classified as $\mathrm{BC}^{\mathrm{s}}$.

By this definition, the majority (348 out of 392) of strains from both countries were $\mathrm{BC}^{\mathrm{s}}$. There were however $24(12.3 \%)$ Swiss and 21 (10.6\%) Finnish strains classified as BC ${ }^{\mathrm{r}}$, with BC MICs ranging from 20 to $>30 \mu \mathrm{g} \mathrm{ml}^{-1}$. The largest group within the Swiss strains $(104 / 195 ; 53.3 \%)$ had BC MICs of $10 \mu \mathrm{g} \mathrm{ml}^{-1}$ whereas the largest group within the Finnish strains (96/197; 48.7\%) had BC MICs of $7.5 \mu \mathrm{g} \mathrm{ml}^{-1}$.

\section{Prevalence of $\mathrm{BC}^{r}$ Strains with Respect to Isolation Sources and Serotypes}

None of the dairy, food animal and other category strains from either Switzerland or Finland from this strain collection exhibited a $\mathrm{BC}^{\mathrm{r}}$ phenotype. In both countries strains exhibiting $\mathrm{BC}^{\mathrm{r}}$ phenotypes were recovered from the FPE, raw meat and RTE food categories. Swiss $\mathrm{BC}^{\mathrm{r}}$ strains also included isolates from human listeriosis cases, whereas the Finnish $\mathrm{BC}^{\mathrm{r}}$ strains included isolates from raw fish, vegetables, and wild birds. The prevalence of $\mathrm{BC}^{\mathrm{r}}$ strains in both countries also varied with regard to the isolation sources (Figure 2A).

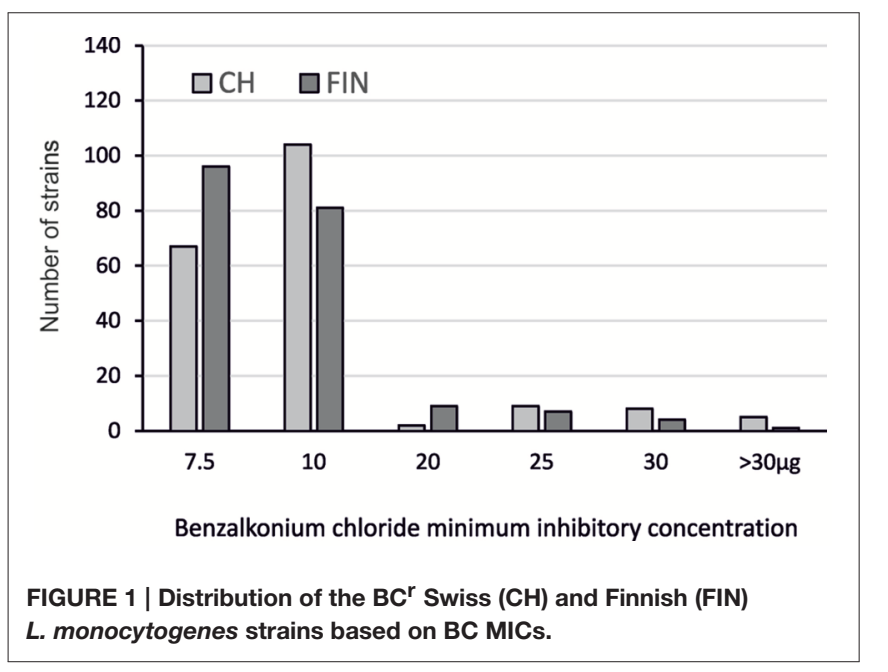

The overall frequency of a $\mathrm{BC}^{\mathrm{r}}$ phenotype in the Swiss strains was $12.3 \%$ and sources included, in descending order of relative frequency: $\operatorname{FPE}(5 / 17,29.4 \%)$, meat $(12 / 59,20.3 \%)$, human isolates $(6 / 80,7.5 \%)$, and RTE food $(1 / 17,5.9 \%)$. The overall frequency of a $\mathrm{BC}^{\mathrm{r}}$ phenotype in the Finnish strains was $10.2 \%$ and the sources included RTE $(2 / 3,66.7 \%)$, vegetables $(3 / 11,27.3 \%)$, the FPE $(5 / 31,16.1 \%)$, fish $(3 / 27,11.1 \%)$, and meat $(4 / 69,5.8 \%)$. Statistical analysis detected significant differences between the prevalence of a $\mathrm{BC}^{\mathrm{r}}$ phenotype in Swiss vs. Finnish strains that were isolated from meat $(\mathrm{CH}>\mathrm{FIN})$ and $\mathrm{RTE}$ $(\mathrm{CH}<\mathrm{FIN})$ food products $(p>0.05)$. It is possible that such differences might have been biased due to discrepancies in the number of tested strains since there were only three Finnish RTE food strains compared to 17 Swiss strains examined in this category. No significant $(p>0.05)$ differences were detected in $\mathrm{BC}^{\mathrm{r}}$ prevalence between the FPE, vegetables and raw fish strain categories in the two countries. $\mathrm{BC}^{\mathrm{r}}$ strain prevalence in human listeriosis $(6 / 80 ; 7.5 \%)$ and bird $(3 / 24 ; 12.5 \%)$ categories in the two countries could however not be compared as they were not represented in both locations.

Prevalence of the $\mathrm{BC}^{\mathrm{r}}$ strains also varied in each country with regard to the different L. monocytogenes serotypes. As expected given the composition of our strain collection, the majority of $\mathrm{BC}^{\mathrm{r}}$ strains detected in both countries belonged to serotypes $1 / 2 \mathrm{a}(28 / 45,62.2 \%)$ and $1 / 2 \mathrm{c}(12 / 45,26.7 \%)$, although $\mathrm{BC}^{\mathrm{r}}$ serotype $4 \mathrm{~b}(3 / 45,6.7 \%)$, and $1 / 2 \mathrm{~b}(2 / 45,4.4 \%)$ strains were also found. Interestingly, the highest prevalence of $\mathrm{BC}$ resistance was detected in serotype $1 / 2 \mathrm{c}$ strains from both countries $(\mathrm{CH}$ 4/16, 25\%; FIN 7/18, 38.9\%; Figure 2B). The second highest BC prevalence in Swiss strains was found in serotype 1/2a strains $(19 / 105,18.1 \%)$, and in Finnish strains among serotype $4 \mathrm{~b}$ strains (3/23, 13\%; Figure 2B). Low prevalence of BC resistance was found in serotype $1 / 2 \mathrm{~b}$ isolates from both countries $(\mathrm{CH}: 1 / 26$, $3.8 \%$; FIN: $1 / 18,5.5 \%)$, and no $\mathrm{BC}^{\mathrm{r}}$ phenotypes were detected in Swiss serotype $4 \mathrm{~b}(n=47)$, as well as serotype $3 \mathrm{a}(n=5)$ strains from both countries. Statistical comparison revealed significantly higher $\mathrm{BC}^{\mathrm{r}}$ prevalence among the Swiss (19/105, 18.1\% vs. $10 / 134,7.5 \% ; p<0.05)$ serotype $1 / 2$ a strains compared to their Finnish counterparts. On the other hand the Swiss serotype $4 \mathrm{~b}$ strains displayed significantly lower $\mathrm{BC}^{\mathrm{r}}$ prevalence (0 vs. $13 \% ; p<0.05)$ compared to those from Finland. No significant differences were observed in $\mathrm{BC}^{\mathrm{r}}$ prevalence associated with serotype $1 / 2 \mathrm{c}$ and $1 / 2 \mathrm{~b}$ strains from the two countries. We are however aware that our observations could be biased due to overall differences in the examined sample sizes between some of the serotype categories in the two countries.

\section{Genotypes Associated with Swiss and Finnish BC ${ }^{r}$ Strains}

Molecular genotypes associated with the Swiss and Finnish $\mathrm{BC}^{\mathrm{r}}$ strains were assessed based on MLST genotyping. The $45 \mathrm{BC}^{\mathrm{r}}$ strains from the two countries were assigned to 14 sequence types (ST), which included two newly described sequence types (ST25, ST28; Table 3). BC $\mathrm{C}^{\mathrm{r}}$ strains in both countries belonged predominantly to sequence types ST121 $(14 / 45 ; 31.1 \%)$ and ST9 $(11 / 45 ; 24.4 \%)$ although there were some country specific 
TABLE 3 | Overview of the Swiss (CH) and Finnish (FIN) BCr strains detected in this study.

\begin{tabular}{|c|c|c|c|c|c|c|c|c|c|c|}
\hline \multirow[t]{2}{*}{ Strain ID } & \multicolumn{2}{|c|}{ Strain origin } & \multirow[t]{2}{*}{ Serotype } & \multicolumn{3}{|c|}{ MLST genotypes ${ }^{a}$} & \multicolumn{2}{|c|}{ BC MIC $\mu \mathrm{gml}^{-1}$} & \multirow{2}{*}{$\begin{array}{l}\text { Efflux pump } \\
\text { dependency }^{b}\end{array}$} & \multirow[t]{2}{*}{ BCr gene $^{\mathrm{C}}$} \\
\hline & Country & Source & & CC & ST & Lineage & BC alone & $\mathrm{BC}$ plus reserpine & & \\
\hline LM116 & FIN & Vegetable & $1 / 2 b$ & CC5 & ST5 & 1 & 25 & 30 & No & Unknown \\
\hline N12-2082 & $\mathrm{CH}$ & Human & $1 / 2 a$ & CC8 & ST8 & 2 & 25 & 30 & No & Unknown \\
\hline LT25E & $\mathrm{FIN}$ & Vegetable & $4 b$ & CC1 & ST515 & 1 & 30 & 30 & No & Unknown \\
\hline LL17/3 & FIN & Wild bird, feces & $4 b$ & CC1 & ST1 & 1 & $>30$ & 30 & Partial & Unknown \\
\hline LT30E & FIN & Vegetable & $1 / 2 a$ & CC8 & ST8 & 2 & 25 & 20 & Partial & Unknown \\
\hline TT107E & FIN & Fish & $1 / 2 a$ & CC155 & ST155 & 2 & 20 & 15 & Partial & Unknown \\
\hline N13-0094 & $\mathrm{CH}$ & Human & $1 / 2 a$ & CC403 & ST403 & 2 & 25 & 20 & Partial & Unknown \\
\hline N12-1667 & $\mathrm{CH}$ & FPE & $1 / 2 a$ & CC403 & ST403 & 2 & 25 & 20 & Partial & Unknown \\
\hline N11-1547 & $\mathrm{CH}$ & Human & $1 / 2 a$ & CC403 & ST403 & 2 & 25 & 20 & Partial & Unknown \\
\hline N12-0935 & $\mathrm{CH}$ & Human & $1 / 2 a$ & CC403 & ST403 & 2 & 25 & 20 & Partial & Unknown \\
\hline Тा82E & FIN & Fish & $1 / 2 a$ & CC155 & ST155 & 2 & 25 & 15 & Yes & Unknown \\
\hline HT45E & FIN & Meat & $1 / 2 a$ & CC155 & ST155 & 2 & 20 & 10 & Yes & Unknown \\
\hline LL66/3 & $\mathrm{FIN}$ & Wild bird, feces & $1 / 2 a$ & CC101 & ST101 & 2 & 20 & 7.5 & Yes & Unknown \\
\hline LL1/3 & FIN & Wild bird, feces & $4 b$ & CC315 & ST194 & 2 & 20 & 5 & Yes & Unknown \\
\hline LM84 & FIN & RTE food & $1 / 2 a$ & CC8 & ST120 & 2 & 25 & 30 & No & emrE \\
\hline LK60/1 & FIN & Fish & $1 / 2 a$ & CC121 & ST121 & 2 & 25 & 30 & No & $\mathrm{qacH}$ \\
\hline N11-1905 & $\mathrm{CH}$ & Meat & $1 / 2 a$ & CC121 & ST121 & 2 & 25 & 30 & No & qacH \\
\hline HL6E & FIN & FPE & $1 / 2 c$ & untypable & untypable & ND & 20 & 20 & No & qacH \\
\hline HE152E & FIN & FPE & $1 / 2 c$ & $\mathrm{CC9}$ & ST9 & 2 & 20 & 20 & No & $q \mathrm{acH}$ \\
\hline HT93E/1 & $\mathrm{FIN}$ & RTE food & $1 / 2 c$ & CC9 & ST9 & 2 & 20 & 20 & No & qacH \\
\hline HT100E/1 & FIN & Meat & $1 / 2 c$ & CC9 & ST9 & 2 & 20 & 20 & No & $q a c H$ \\
\hline L34-s & FIN & Meat & $1 / 2 a$ & CC121 & ST121 & 2 & 30 & 30 & No & $q a c H$ \\
\hline MJL14 & FIN & FPE & $1 / 2 a$ & CC121 & ST121 & 2 & 30 & 30 & No & qacH \\
\hline HT65E/1 & FIN & Meat & $1 / 2 a$ & CC121 & ST121 & 2 & 30 & 30 & No & qacH \\
\hline N13-0119 & $\mathrm{CH}$ & Human & $1 / 2 \mathrm{a}$ & CC121 & ST121 & 2 & 30 & 30 & No & $\mathrm{qacH}$ \\
\hline N12-0367 & $\mathrm{CH}$ & Human & $1 / 2 a$ & CC121 & ST121 & 2 & 30 & 30 & No & $q a c H$ \\
\hline $\operatorname{Lm} 760$ & $\mathrm{CH}$ & Meat & $1 / 2 c$ & CC9 & ST9 & 2 & 20 & 20 & No & $q \mathrm{acH}$ \\
\hline N11-2543 & $\mathrm{CH}$ & FPE & $1 / 2 a$ & CC121 & ST121 & 2 & 30 & 30 & No & qacH \\
\hline N12-0571 & $\mathrm{CH}$ & Meat & $1 / 2 a$ & CC121 & ST121 & 2 & 30 & 30 & No & $q a c H$ \\
\hline Lm S1 & $\mathrm{CH}$ & FPE & $1 / 2 a$ & CC121 & ST121 & 2 & 30 & 30 & No & $q a c H$ \\
\hline N11-1218 & $\mathrm{CH}$ & Meat & $1 / 2 a$ & CC121 & ST25 & 2 & $>30$ & 30 & Partial & $\mathrm{qacH}$ \\
\hline HT69E & FIN & Meat & $1 / 2 c$ & CC9 & ST9 & 2 & 20 & 15 & Partial & qacH \\
\hline HE28E & $\mathrm{FIN}$ & FPE & $1 / 2 c$ & CC9 & ST9 & 2 & 25 & 20 & Partial & $q a c H$ \\
\hline Lm 217 & $\mathrm{CH}$ & Meat & $1 / 2 a$ & CC9 & ST9 & 2 & 25 & 20 & Partial & $q a c H$ \\
\hline Lm 25/9 & $\mathrm{CH}$ & Meat & $1 / 2 c$ & $\mathrm{CC9}$ & ST9 & 2 & 20 & 15 & Partial & $q a c H$ \\
\hline Lm 89 & FIN & FPE & $1 / 2 c$ & CC9 & ST9 & 2 & 25 & 20 & Partial & $\mathrm{qacH}$ \\
\hline N12-0494 & $\mathrm{CH}$ & Meat & $1 / 2 a$ & CC121 & ST121 & 2 & 25 & 20 & Partial & $q a c H$ \\
\hline N12-2229 & $\mathrm{CH}$ & RTE food & $1 / 2 a$ & CC121 & ST121 & 2 & 25 & 30 & No & brcABC \\
\hline N12-0644 & $\mathrm{CH}$ & Meat & $1 / 2 c$ & CC9 & ST9 & 2 & $>30$ & $>30$ & No & brcABC \\
\hline N12-2271 & $\mathrm{CH}$ & Meat & $1 / 2 c$ & CC9 & ST9 & 2 & $>30$ & $>30$ & No & brcABC \\
\hline N12-2118 & $\mathrm{CH}$ & Meat & $1 / 2 a$ & CC121 & ST121 & 2 & 30 & 30 & No & brcABC \\
\hline N13-0288 & $\mathrm{CH}$ & Meat & $1 / 2 a$ & CC121 & ST28 & 2 & 30 & 30 & No & brcABC \\
\hline N13-0369 & $\mathrm{CH}$ & Meat & $1 / 2 a$ & CC121 & ST121 & 2 & 30 & 30 & No & brcABC \\
\hline Lm S9 & $\mathrm{CH}$ & FPE & $1 / 2 a$ & CC204 & ST204 & 2 & $>30$ & $>30$ & No & brcABC \\
\hline Lm S2 & $\mathrm{CH}$ & FPE & $1 / 2 b$ & CC5 & ST5 & 1 & $>30$ & 30 & No & brcABC \\
\hline
\end{tabular}

${ }^{a}$ MLST types and genetic lineages were assigned based on the L. monocytogenes MLST database website (http://bigsdb.web.pasteur.fr).

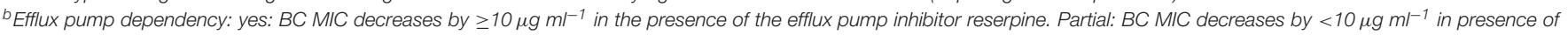
reserpine. No: $B C$ MIC was not affected by the presence of reserpine.

${ }^{c} B C^{r}$ gene presence determined by PCR. 

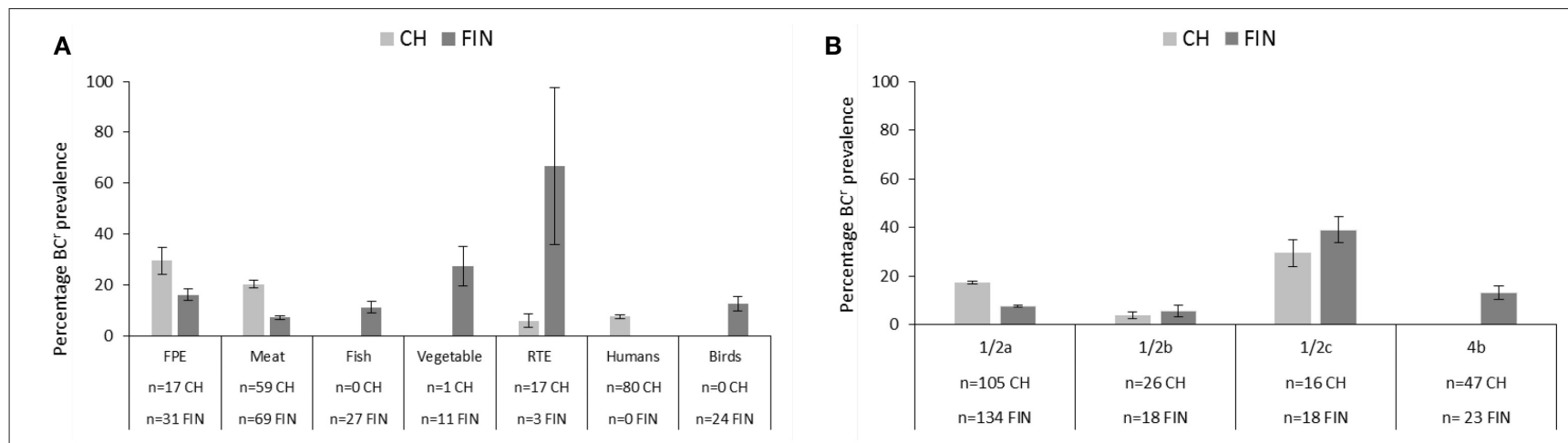

FIGURE 2 | Bar charts depicting the prevalence (including 95\% Cls) and distribution of BCr among Swiss and Finnish L. monocytogenes strains based on $(\mathbf{A})$ isolation sources and $(\mathbf{B})$ serotypes.

differences. Sequence type 121 (50 vs. 19\%) predominated among the Swiss BC ${ }^{\mathrm{r}}$ strains while ST9 (28.6 vs. $20.8 \%$ ) was predominant in Finnish BC $\mathrm{B}^{\mathrm{r}}$ strains. Sequence types ST403 $(n=4)$, ST204 $(n=1)$, ST25 $(n=1)$, and ST $28(n=1)$ were exclusive to Swiss $\mathrm{BC}^{\mathrm{r}}$ strains whereas ST155 $(n=3), \mathrm{ST} 1(n=1), \mathrm{ST} 101(n=1)$, ST120 $(n=1), \operatorname{ST} 194(n=1)$, and ST515 $(n=1)$ were exclusive to the Finnish $\mathrm{BC}^{\mathrm{r}}$ strains. Strains were grouped into 10 MLST clonal complexes based on their sequence types showing that $\mathrm{BC}^{\mathrm{r}}$ in this strain collection is mainly associated with serotype $1 / 2 \mathrm{a}, \mathrm{CC} 121(16 / 45 ; 35.6 \%)$ and serotype $1 / 2 \mathrm{c}$, CC9 $(11 / 45$, $24.4 \%)$. Overall, most $\mathrm{BC}^{\mathrm{r}}$ strains belonged to evolutionary genetic lineage II $(39 / 45 ; 86.7 \%)$. There were only five $(11.1 \%)$ genetic lineage $\mathrm{I} \mathrm{BC}^{\mathrm{r}}$ strains observed, one of which was isolated in Switzerland and four were from Finland. One serotype $1 / 2 \mathrm{c}$ strain that originated from a FPE in Finland was untypable using the current MLST scheme. In this strain, primers for one ( $b g l A$ ) out of the seven MLST genes amplified a PCR product bearing a sequence that is unrelated to the L. monocytogenes bglA gene.

\section{Prevalence of BC Resistance Genes in Swiss and Finnish $\mathrm{BC}^{r}$ Strains}

Benzalkonium chloride resistant strains were also examined for the distribution of genes encoding the three efflux pump systems ( $b r c A B C, q a c H$, and emrE) currently known to confer $\mathrm{BC}$ resistance in $L$. monocytogenes (Table 3 ). The PCR-based analysis detected genes associated with such efflux pump systems in $79 \%(19 / 24)$ Swiss and 57\% (12/21) Finnish BC B $^{\mathrm{r}}$ strains, respectively. Swiss strains harbored both qacH (11/24; 45.8\%) and $\operatorname{brc} A B C(8 / 24,33.3 \%)$ associated genes, and no strains harboring emrE were found. A majority of the $\mathrm{BC}^{\mathrm{r}}$ strains from Finland harbored qacH genes $(11 / 21 ; 52.4 \%)$, no bcrABC genes were found, and in one $\mathrm{BC}^{\mathrm{r}}$ strain, an emrE gene was detected. With respect to associated serotypes and MLST genotypes, the $q a c H$ genes were detected in serotype 1/2a, CC121 (ST121 and ST28), serotype 1/2a, CC204 (ST204), and serotype 1/2c, CC9 (ST9) strains. The $\operatorname{brcABC}$ genes were associated with serotype 1/2a, CC121 (ST121 and ST25), serotype 1/2b, CC5, and serotype 1/2c, CC9 strains. The emrE gene was associated with a serotype 1/2a, CC8 (ST120) strain. In terms of origins, the qacH-encoding strains came from FPE, raw meat, fish RTE food, and human listeriosis cases. The $\operatorname{brc} A B C$ harboring strains were from FPE and raw meat, and the emrE strain originated from an RTE food product. None of the three known $\mathrm{BC}$ resistance determinants were detected in $21 \%(5 / 24)$ and $43 \%(9 / 21)$ of the Swiss and Finnish $\mathrm{BC}^{\mathrm{r}}$ strains, respectively (Table 3). This group included serotype 4b, CC1 (ST1 and ST515), serotype 1/2a, CC8 (ST8), CC101 (ST101), CC155 (ST155), and serotype $1 / 2 \mathrm{~b}$, CC5 (ST5) strains, which were isolated from diverse sources. At this stage, sequence alterations affecting PCR primer binding sites across different strains cannot be completely ruled out as a possible reason for false negative results in some of the $\mathrm{BC}^{\mathrm{r}}$ strains found to lack the known $\mathrm{BC}^{\mathrm{r}}$ genes.

\section{Role of Efflux Pump Activity in Swiss and Finnish BCr Strains}

A screen with reserpine showed that the $\mathrm{BC}$ resistance in 4 out of 45 strains depended on reserpine sensitive efflux pump systems. The BC resistance in an additional 14 strains was classified as partially efflux pump dependent while the addition of reserpine had no effect on the BC MIC in 27 strains. As mentioned above, a subset of $14 \mathrm{BC}^{\mathrm{r}}$ strains lacked known $\mathrm{BC}$ resistance genes. Reserpine addition had no impact on BC MICs in four of those strains. The $\mathrm{BC}$ resistance in an additional three strains was classified as efflux pump dependent, and in seven strains as partially efflux dependent. (Table 3).

\section{DISCUSSION}

In this study 392 L. monocytogenes strains recovered from human clinical listeriosis, food products and production environments, food animals, and wild birds in Switzerland and Finland were analyzed with respect to BC resistance. The strain collections could not be exactly matched or balanced with respect to origin, due to country specific differences in the type of food 
typically produced and limited availability of isolates. Although it remains unclear how well the strain collection represents the true distribution of strains in these two geographical locations, the large number of strains included in this study is likely to balance some of the potential bias. The vast majority of analyzed strains belonged to serotype $1 / 2 \mathrm{a}, 1 / 2 \mathrm{~b}, 1 / 2 \mathrm{c}$, and $4 \mathrm{~b}$, which are typical $L$. monocytogenes serotypes found in food, the food processing environment and human clinical cases (Orsi et al., 2011).

The prevalence of $\mathrm{BC}^{\mathrm{r}}$ strains of $11.4 \%$ amongst our strains is at the lower end of what other authors have found. In comparison, prevalences of BC-resistant strains determined in other studies range from $\sim 10 \%$ in strains isolated from fish and poultry factories (Aase et al., 2000), human clinical cases and food (Mereghetti et al., 2000; Ratani et al., 2012); $18-26 \%$ in strains isolated from food in Switzerland (Ebner et al., 2015) and China (Xu et al., 2014; Jiang et al., 2016) to $61 \%$ in strains originating from fish processing (Soumet et al., 2005) and the human clinical, food, and food production environment (Mullapudi et al., 2008; Dutta et al., 2013). These differences are partially due to the different methods used as well as differences in the definition of resistance across studies. The range of cutoffs for BC-resistance from 4 to $16 \mu \mathrm{g} \mathrm{ml}^{-1}$ in these studies (Aase et al., 2000; Mereghetti et al., 2000; Soumet et al., 2005; Mullapudi et al., 2008; Dutta et al., 2013; $\mathrm{Xu}$ et al., 2014; Ebner et al., 2015; Jiang et al., 2016) is a consequence of the commonly used method to determine BCresistance relative to the $\mathrm{MIC}$ that inhibits a majority of strains. Working concentrations of BC in commercial products used in the food processing environment typically range from 500 to $1,000 \mu \mathrm{g} \mathrm{ml}^{-1}$ (Hegstad et al., 2010). However, L. monocytogenes preferably survives in niches with low accessibility for cleaning where the actual concentration of disinfectants is hard to predict. Defining relative cutoffs for BC-resistance is therefore a reasonable approach to focus on the strains that are most likely to have a selective advantage during repeated disinfection procedures.

There was no clear correlation between resistance to BC and country of origin. In our study, serotype $1 / 2 \mathrm{a}$ comprised the largest number of $\mathrm{BC}^{\mathrm{r}}$ strains although the relative prevalence of $\mathrm{BC}^{\mathrm{r}}$ was highest among the serotype $1 / 2 \mathrm{c}$ strains. Other authors have found varying fractions of $\mathrm{BC}^{\mathrm{r}}$ serotype $1 / 2 \mathrm{a}, 1 / 2 \mathrm{~b}, 1 / 2 \mathrm{c}$, and $4 \mathrm{~b}$ strains of L. monocytogenes (ranging from 7 to $60 \%$ for serotype $1 / 2 \mathrm{a}$; from 0 to $51 \%$ for serotype $1 / 2 \mathrm{~b}$; from 22 to $75 \%$ for serotype $1 / 2 \mathrm{c}$ and from 0 to $100 \%$ for serotype $4 \mathrm{~b}$; Mereghetti et al., 2000; Romanova et al., 2002; Soumet et al., 2005; Mullapudi et al., 2008; Ratani et al., 2012; Xu et al., 2014; Jiang et al., 2016). This wide range is to be expected, given the often relatively small sample sizes and the low discriminatory power of serotyping (Datta et al., 2013).

In contrast, analysis by MLST revealed that CC121 and CC9 are overrepresented among $\mathrm{BC}^{\mathrm{r}}$ strains carrying $\operatorname{brc} A B C$ and $q a c H$ genes, which confirms the results of an earlier Swiss study (Ebner et al., 2015). Both of these clonal complexes are commonly found worldwide in association with food and clinical cases (Chenal-Francisque et al., 2011). A large study analyzing the population biology of 1696 strains of L. monocytogenes by core genome MLST indicated a broad range of strains carrying $\operatorname{brc} A B C$ and $q a c H$ genes (including a cluster of CC121 strains) while emrE seems to be limited to sublineage 8 strains (comprising CC8, ST120; Moura et al., 2016). Incidentally, the only strain in our panel carrying the emrE gene also belongs to CC8, ST120. None of the $\mathrm{BC}^{\mathrm{r}}$ strains lacking $\operatorname{brc} A B C$, emrE, and $q a c H$ belonged to CC121 or CC9. Instead, these strains belong to a more diverse set of seven sequence types including a cluster of four CC403 strains, a clonal complex that seems to be relatively rare and largely found in Europe with only five entries in the MLST database of the Institute Pasteur (http://bigsdb.web.pasteur.fr).

Our dataset provides several lines of evidence for mechanisms of $\mathrm{BC}$ resistance other than the known efflux pumps that may work either alone or in conjunction with the products of the $b c r A B C, q a c H$, and emrE genes. (i) Fourteen $\mathrm{BC}^{\mathrm{r}}$ strains carried none of the known $\mathrm{BC}$ efflux pumps as determined by PCR. (ii) In eleven of these strains, reserpine screening indicated that efflux pumps other than those coded by emrE, $b c r A B C$, and $q a c H$ play at least a partial role in conferring resistance to $\mathrm{BC}$. (iii) Out of the $31 \mathrm{BC}^{\mathrm{r}}$ strains carrying genes encoding for known efflux pumps, 24 showed no reduction of the $\mathrm{BC}$ MIC in the presence of reserpine. This may indicate the presence of additional, yet unknown genes that confer BC resistance via a mechanism other than efflux pumps in these strains. Alternatively, reserpine may not be equally effective against all efflux pumps. In fact, other authors (Ortiz et al., 2015) found no difference in BC MIC after the addition of reserpine in a strain carrying the Tn6188 transposon (coding for qacH Müller et al., 2013), and a study analyzing efflux pumps conferring multidrug resistance to Staphylococcus aureus showed that reserpine failed to identify their presence in a considerable number (72/128, 61\%) of strains (Frempong-Manso et al., 2009). While the addition of reserpine might not be a reliable method to exclude the presence of efflux pumps, in instances where it does exert an effect on the MIC of a given antimicrobial the presence of efflux pumps can be assumed (Godreuil et al., 2003; Soumet et al., 2005; Romanova et al., 2006; Xu et al., 2014).

Further, analysis of the $\mathrm{BC}^{\mathrm{r}}$ strains in our panel that do not code for $b c r A B C, q a c H$, and emrE genes might help identify these additional factors involved in BC resistance. For instance, increased transcription of the multidrug resistance transporter lde has been reported in response to $\mathrm{BC}$ (RakicMartinez et al., 2011). Other than the activity of efflux pumps, modifications of the cell wall may potentially increase tolerance of BC by L. monocytogenes (McDonnell and Russell, 1999). This is supported by evidence from several studies: Mereghetti et al. (2000) observed an association between $\mathrm{BC}$ resistance and failure of phage-based subtyping methods, which may indicate modifications in the wall teichoic acids. In addition, transcriptional analysis of the response to QAC revealed upregulation of peptidoglycan synthesis pathways (Fox et al., 2011), and To et al. (2002) found a shift in fatty acid composition in one $\mathrm{BC}$-adapted strain compared to the parent strain. 
In conclusion, $\mathrm{BC}^{\mathrm{r}}$ strains of L. monocytogenes are present and should be monitored in the Swiss and Finnish food production environment with a special focus on strains that belong to CC9 and CC121. One strain from Finland carried the emrE gene, which to our knowledge is the first time the emrE gene has been described in a strain of L. monocytogenes originating outside of Canada. Additionally, we found $\mathrm{BC}$ resistance in strains lacking all of the known $\mathrm{BC}$ resistance genes, indicating the presence of yet unknown mechanisms of $\mathrm{BC}$ resistance.

\section{AUTHOR CONTRIBUTIONS}

TT and HK designed and supervised the study. ABM, AM, and AP performed the experiments. ABM, TT, HK, and CG analyzed the data and wrote the manuscript.

\section{REFERENCES}

Aase, B., Sundheim, G., Langsrud, S., and Rørvik, L. M. (2000). Occurrence of and a possible mechanism for resistance to a quaternary ammonium compound in Listeria monocytogenes. Int. J. Food Microbiol. 62, 57-63. doi: 10.1016/S01681605(00)00357-3

Bergholz, T. M., den Bakker, H. C., Fortes, E. D., Boor, K. J., and Wiedmann, M. (2010). Salt stress phenotypes in Listeria monocytogenes vary by genetic lineage and temperature. Foodborne. Pathog. Dis. 7, 1537-1549. doi: 10.1089/ fpd.2010.0624

Chenal-Francisque, V., Lopez, J., Cantinelli, T., Caro, V., Tran, C., Leclercq, A., et al. (2011). Worldwide distribution of major clones of Listeria monocytogenes. Emerg. Infect. Dis. 17, 1110-1112. doi: 10.3201/eid/1706.101778

Crim, S. M., Griffin, P. M., Tauxe, R., Marder, E. P., Gilliss, D., Cronquist, A. B. et al. (2015). Preliminary incidence and trends of infection with pathogens transmitted commonly through food - Foodborne diseases active surveillance network, 10 U.S. sites, 2006-2014. MMWR. Morb. Mortal. Wkly. Rep. 64, 495-499.

Datta, A. R., Laksanalamai, P., and Solomotis, M. (2013). Recent developments in molecular sub-typing of Listeria monocytogenes. Food Addit. Contam. Part A Chem. Anal. Control Expo. Risk Assess. 30, 1437-1445. doi: 10.1080/19440049. 2012.728722

de Valk, H., Jacquet, C., Goulet, V., Vaillant, V., Perra, A., Simon, F., et al. (2005). Surveillance of Listeria infections in Europe. Eur. Surveill. 10, 251-255. Available online at: http://www.eurosurveillance.org/images/ dynamic/EQ/v05n04/v05n04.pdf

Dutta, V., Elhanafi, D., and Kathariou, S. (2013). Conservation and distribution of the benzalkonium chloride resistance cassette bcrABC in Listeria monocytogenes. Appl. Environ. Microbiol. 79, 6067-6074. doi: 10.1128/ AEM.01751-13

Ebner, R., Stephan, R., Althaus, D., Brisse, S., Maury, M., and Tasara, T. (2015). Phenotypic and genotypic characteristics of Listeria monocytogenes strains isolated during 2011-2014 from different food matrices in Switzerland. Food Control 57, 321-326. doi: 10.1016/j.foodcont.2015. 04.030

Elhanafi, D., Dutta, V., and Kathariou, S. (2010). Genetic characterization of plasmid-associated benzalkonium chloride resistance determinants in a Listeria monocytogenes strain from the 1998-1999 outbreak. Appl. Environ. Microbiol. 76, 8231-8238. doi: 10.1128/AEM.02056-10

Ferreira, V., Wiedmann, M., Teixeira, P., and Stasiewicz, M. J. (2014). Listeria monocytogenes persistence in food-associated environments: epidemiology, strain characteristics, and implications for public health. J. Food Prot. 77, 150-170. doi: 10.4315/0362-028X.JFP-13-150

Fox, E. M., Leonard, N., and Jordan, K. (2011). Physiological and transcriptional characterization of persistent and non-persistent Listeria monocytogenes

\section{FUNDING}

ABM was partly funded by the University of Zurich.

\section{ACKNOWLEDGMENTS}

We thank the team of curators of the Institute Pasteur MLST and genome databases for curating the data and making them publicly available at http://bigsdb.web.pasteur.fr.

\section{SUPPLEMENTARY MATERIAL}

The Supplementary Material for this article can be found online at: http://journal.frontiersin.org/article/10.3389/fmicb. 2017.00397/full\#supplementary-material

isolates. Appl. Environ. Microbiol. 77, 6559-6569. doi: 10.1128/AEM. 05529-11

Frempong-Manso, E., Raygada, J. L., DeMarco, C. E., Seo, S. M., and Kaatz, G. W. (2009). Inability of a reserpine-based screen to identify strains overexpressing efflux pump genes in clinical isolates of Staphylococcus aureus. Int. J. Antimicrob. Agents 33, 360-363. doi: 10.1016/j.ijantimicag.2008.10.016

Gilmoure, M. W., Graham, M., Van Domselaar, G., Tyler, S., Kent, H., TroutYakel, K. M., et al. (2010). High-throughput genome sequencing of two Listeria monocytogenes clinical isolates during a large foodborne outbreak. BMC.Genomics 11:120. doi: 10.1186/1471-2164-11-120

Godreuil, S., Galimand, M., Gerbaud, G., Jacquet, C., and Courvalin, P. (2003). Efflux pump Lde is associated with fluoroquinolone resistance in Listeria monocytogenes. Antimicrob. Agents Chemother. 47, 704-708. doi: 10.1128/AAC.47.2.704-708.2003

Hegstad, K., Langsrud, S., Lunestad, B. T., Scheie, A. A., Sunde, M., and Yazdankhah, S. P. (2010). Does the wide use of quaternary ammonium compounds enhance the selection and spread of antimicrobial resistance and thus threaten our health? Microb. Drug Resist. 16, 91-104. doi: 10.1089/mdr. 2009.0120

Jiang, X., Yu, T., Liang, Y., Ji, S., Guo, X., Ma, J., et al. (2016). Efflux pump-mediated benzalkonium chloride resistance in Listeria monocytogenes isolated from retail food. Int. J. Food Microbiol. 217, 141-145. doi: 10.1016/ j.ijfoodmicro.2015.10.022

Kovacevic, J., Mesak, L. R., and Allen, K. J. (2012). Occurrence and characterization of Listeria spp. in ready-to-eat retail foods from Vancouver, British Columbia. Food Microbiol. 30, 372-378. doi: 10.1016/j.fm.2011.12.015

Kovacevic, J., Ziegler, J., Walecka-Zacharska, E., Reimer, A., Kitts, D. D., and Gilmour, M. W. (2015). Tolerance of Listeria monocytogenes to quaternary ammonium sanitizers is mediated by a novel efflux pump encoded by emrE. Appl. Environ. Microbiol. 82, 939-953. doi: 10.1128/AEM.03741-15

Langsrud, S., Sidhu, M. S., Heir, E., and Holck, A. (2003). Bacterial disinfectant resistance- a challenge for the food industry. Int. Biodeterior. Biodegradation 51, 283-290. doi: 10.1016/S0964-8305(03)00039-8

Maertens de Noordhout, C., Devleesschauwer, B., Angulo, F. J., Verbeke, G., Haagsma, J., Kirk, M., et al. (2014). The global burden of listeriosis: a systematic review and meta-analysis. Lancet Infect. Dis. 14, 1073-1082. doi: 10.1016/ S1473-3099(14)70870-9

McDonnell, G., and Russell, A. D. (1999). Antiseptics and disinfectants: activity, action, and resistance. Clin. Microbiol. Rev. 12, 147-179.

Mereghetti, L., Quentin, R., Marquet-Van Der Mee, N., and Audurier, A. (2000). Low sensitivity of Listeria monocytogenes to quaternary ammonium compounds. Appl. Environ. Microbiol. 66, 5083-5086. doi: 10.1128/AEM.66. 11.5083-5086.2000

Moura, A., Criscuolo, A., Pouseele, H., Maury, M. M., Leclercq, A., Tarr, C., et al. (2016). Whole genome-based population biology and epidemiological 
surveillance of Listeria monocytogenes. Nat. Microbiol. 2:16185. doi: 10.1038/ nmicrobiol.2016.185

Mullapudi, S., Siletzky, R. M., and Kathariou, S. (2008). Heavy-metal and benzalkonium chloride resistance of Listeria monocytogenes isolates from the environment of turkey-processing plants. Appl. Environ. Microbiol. 74, 1464-1468. doi: 10.1128/AEM.02426-07

Müller, A., Rychli, K., Muhterem-Uyar, M., Zaiser, A., Stessl, B., Guinane, C. M., et al. (2013). Tn6188 - a novel transposon in Listeria monocytogenes responsible for tolerance to benzalkonium chloride. PLoS ONE 8:e76835. doi: 10.1371/journal.pone.0076835

Orsi, R. H., den Bakker, H. C., and Wiedmann, M. (2011). Listeria monocytogenes lineages: Genomics, evolution, ecology, and phenotypic characteristics. Int. J. Med. Microbiol. 301, 79-96. doi: 10.1016/j.ijmm.2010.05.002

Ortiz, S., Lopez-Alonso, V., Rodriguez, P., and Martinez-Suarez, J. V. (2015). The connection between persistent, disinfectant-resistant Listeria monocytogenes strains from two geographically separate iberian pork processing plants: evidence from comparative genome analysis. Appl. Environ. Microbiol. 82, 308-317. doi: 10.1128/AEM.02824-15

Popovic, I., Heron, B., and Covacin, C. (2014). Listeria: an Australian perspective (2001-2010). Foodborne. Pathog. Dis. 11, 425-432. doi: 10.1089/fpd.2013.1697

Ragon, M., Wirth, T., Hollandt, F., Lavenir, R., Lecuit, M., Le, M., et al. (2008). A new perspective on Listeria monocytogenes evolution. PLoS Pathog. 4:e1000146. doi: 10.1371/journal.ppat.1000146

Rakic-Martinez, M., Drevets, D. A., Dutta, V., Katic, V., and Kathariou, S. (2011). Listeria monocytogenes strains selected on ciprofloxacin or the disinfectant benzalkonium chloride exhibit reduced susceptibility to ciprofloxacin, gentamicin, benzalkonium chloride, and other toxic compounds. Appl. Environ. Microbiol. 77, 8714-8721. doi: 10.1128/AEM.05941-11

Ratani, S. S., Siletzky, R. M., Dutta, V., Yildirim, S., Osborne, J. A., Lin, W., et al. (2012). Heavy metal and disinfectant resistance of Listeria monocytogenes from foods and food processing plants. Appl. Environ. Microbiol. 78, 6938-6945. doi: 10.1128/AEM.01553-12

Romanova, N. A., Wolffs, P. F., Brovko, L. Y., and Griffiths, M. W. (2006). Role of efflux pumps in adaptation and resistance of Listeria monocytogenes to benzalkonium chloride. Appl. Environ. Microbiol. 72, 3498-3503. doi: 10.1128/AEM.72.5.3498-3503.2006

Romanova, N., Favrin, S., and Griffiths, M. W. (2002). Sensitivity of Listeria monocytogenes to sanitizers used in the meat processing industry. Appl. Environ. Microbiol. 68, 6405-6409. doi: 10.1128/AEM.68.12.6405-6409.2002

Smith, J. L., Liu, Y., and Paoli, G. C. (2013). How does Listeria monocytogenes combat acid conditions? Can. J. Microbiol. 59, 141-152. doi: 10.1139/cjm2012-0392

Soumet, C., Ragimbeau, C., and Maris, P. (2005). Screening of benzalkonium chloride resistance in Listeria monocytogenes strains isolated during cold smoked fish production. Lett. Appl. Microbiol. 41, 291-296. doi: 10.1111/ j.1472-765X.2005.01763.x

To, M. S., Favrin, S., Romanova, N., and Griffiths, M. W. (2002). Postadaptational resistance to benzalkonium chloride and subsequent physicochemical modifications of Listeria monocytogenes. Appl. Environ. Microbiol. 68, 5258-5264. doi: 10.1128/AEM.68.11.5258-5264.2002

Walker, S. J., Archer, P., and Banks, J. G. (1990). Growth of Listeria monocytogenes at refrigeration temperatures. J. Appl. Bacteriol. 68, 157-162. doi: 10.1111/j.1365-2672.1990.tb02561.x

Xu, D., Li, Y., Zahid, M. S., Yamasaki, S., Shi, L., Li, J. R., et al. (2014). Benzalkonium chloride and heavy-metal tolerance in Listeria monocytogenes from retail foods. Int. J. Food Microbiol. 190, 24-30. doi: 10.1016/j.ijfoodmicro.2014.08.017

Conflict of Interest Statement: The authors declare that the research was conducted in the absence of any commercial or financial relationships that could be construed as a potential conflict of interest.

Copyright (c) 2017 Meier, Guldimann, Markkula, Pöntinen, Korkeala and Tasara. This is an open-access article distributed under the terms of the Creative Commons Attribution License (CC BY). The use, distribution or reproduction in other forums is permitted, provided the original author(s) or licensor are credited and that the original publication in this journal is cited, in accordance with accepted academic practice. No use, distribution or reproduction is permitted which does not comply with these terms. 